\title{
What Adverse Events and Injuries Are Cited in Anesthesia Malpractice Claims for Nonspine Orthopaedic Surgery?
}

\author{
Christopher D. Kent MD, Linda S. Stephens PhD, Karen L. Posner PhD, \\ Karen B. Domino MD, MPH
}

Published online: 2 March 2017

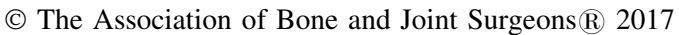

\begin{abstract}
Background Malpractice claims that arise during the perioperative care of patients receiving orthopaedic procedures will frequently involve both orthopaedic surgeons and anesthesiologists. The Anesthesia Closed Claims database contains anesthesia malpractice claim data that can be used to investigate patient safety events arising during the care of orthopaedic patients and can provide insight into the medicolegal liability shared by the two specialties.

Questions/Purposes (1) How do orthopaedic anesthetic malpractice claims differ from other anesthesia claims with regard to patient and case characteristics, common events and injuries, and liability profile? (2) What are the characteristics of patients who had neuraxial hematomas after spinal and epidural anesthesia for orthopaedic procedures? (3) What are the characteristics of patients who had orthopaedic anesthesia malpractice claims for central ischemic neurologic injury occurring during shoulder
\end{abstract}

The institution of one or more of the authors (LSS, KLP, KBD) has received funding from the American Society of Anesthesiologists (ASA) and the Anesthesia Quality Institute (AQI; Schaumburg, IL, USA). All opinions expressed are those of the authors and do not reflect the policy of the ASA or AQI.

All ICMJE Conflict of Interest Forms for authors and Clinical Orthopaedics and Related Research $\AA$ editors and board members are on file with the publication and can be viewed on request. Each author certifies that his or her institution approved the human protocol for this investigation, that all investigations were conducted in conformity with ethical principles of research, and that a waiver of informed consent for participation in the study was obtained.

C. D. Kent, L. S. Stephens, K. L. Posner, K. B. Domino ( $ه)$

Department of Anesthesiology and Pain Medicine, University of Washington, Box 356540, Seattle, WA 98195-6540, USA

e-mail:kdomino@uw.edu surgery in the beach chair position? (4) What are the characteristics of patients who had malpractice claims for respiratory depression and respiratory arrests in the postoperative period?

Methods The Anesthesia Closed Claims Project database was the source of data for this study. This national database derives data from a panel of liability companies (national and regional) and includes closed malpractice claims against anesthesiologists representing $>30 \%$ of practicing anesthesiologists in the United States from all types of practice settings (hospital, surgery centers, and offices). Claims for damage to teeth or dentures are not included in the database. Patient characteristics, type of anesthesia, damaging events, outcomes, and liability characteristics of anesthesia malpractice claims for events occurring in the years 2000 to 2013 related to nonspine orthopaedic surgery $(\mathrm{n}=475)$ were compared with claims related to other procedures $(\mathrm{n}=1592)$ with $\mathrm{p}<0.05$ as the criterion for statistical significance and two-tailed tests. Odds ratios and their 95\% confidence intervals were calculated for all comparisons. Three types of claims involving high-impact injuries in patients undergoing nonspine orthopaedic surgery were identified through database query for in-depth descriptive review: neuraxial hematoma $(n=10)$, central ischemic neurologic injury in the beach chair position $(\mathrm{n}=$ 9), and injuries caused by postoperative respiratory depression $(\mathrm{n}=23)$.

Results Nonspine orthopaedic anesthesia malpractice claims were more frequently associated with nerve injuries (125 of 475 [26\%], odds ratio [OR] 2.12 [1.66-2.71]) and events arising from the use of regional anesthesia (125 of 475 [26\%], OR 6.18 (4.59-8.32) than in malpractice claims in other areas of anesthesia malpractice (230 of 1592 [14\%] and 87 of 1592 [6\%], respectively, $p<0.001$ for both comparisons). Ninety percent (nine of 10) of patients with 
claims for neuraxial hematomas were receiving anticoagulant medication and all had severe long-term injuries, most with a history of significant delay in diagnosis and treatment after first appearance of signs and symptoms. Central ischemic injuries occurring during orthopaedic surgery in the beach chair position did not occur solely in patients who would have been considered at high risk for ischemic stroke. Patients with malpractice claims for injuries resulting from postoperative respiratory depression events had undergone lower extremity procedures (20 of 23 [87\%]) and most events (22 of 23 [96\%]) occurred on the day of surgery or the first postoperative day.

Conclusions Nonspine orthopaedic anesthesia malpractice claims more frequently cited nerve injury and events arising from the use of regional anesthesia than other surgical anesthesia malpractice claims. This may reflect the frequency of regional anesthesia in orthopaedic cases rather than increased risk of injury associated with regional techniques. When neuraxial procedures and anticoagulation regimens are used concurrently, care pathways should emphasize clear lines of responsibility for coordination of care and early investigation of any unusual neurologic findings that might indicate neuraxial hematoma. We do not have a good understanding of the factors that render some patients vulnerable to the rare occurrence of intraoperative central ischemic injury in the beach chair position, but providers should carefully calculate cerebral perfusion pressure relative to measured blood pressure for patients in the upright position. Postoperative use of multiple opioids by different concurrent modes of administration warrant special precautions with consideration given to the provision of care in settings with enhanced respiratory monitoring. The limitations of retrospective closed claims database review prevent conclusions regarding causation. Nonetheless, the collection of relatively rare events with substantial clinical detail provides valuable data to generate hypotheses about causation with potential for future study to improve patient safety. Level of Evidence Level III, therapeutic study.

\section{Introduction}

Analysis of malpractice claims has been successfully used by anesthesiologists to improve patient safety and reduce liability [3]. Findings have been used to support various clinical practice standards, guidelines, and advisories by the American Society of Anesthesiologists [4]. Similar efforts to leverage lessons learned from malpractice claims have been used in other specialties [15-17, 26, 36] and countries [7, 35]. Numerous studies of malpractice claims in the United States provide insight into the malpractice profile of orthopaedics among the various medical specialties. A random sample of claims from five US insurers found orthopaedic surgery to represent $8 \%$ of 1452 total claims [40], whereas a study of the National Practitioner Databank of paid malpractice claims showed orthopaedics to represent $7 \%$ of physicians with one or more claims [39]. A separate study from a single large physician-owned liability carrier in the United States found orthopaedic surgery to represent $10.5 \%$ of 26,853 claims with orthopaedic surgeons ranking fourth among specialists (after pediatrics, obstetrics, and urology) in the proportion of a physician's career spent with an open malpractice claim [37]. Orthopaedic surgery ranked fourth among specialties (after neurosurgery, thoracic-cardiovascular surgery, and general surgery) in the proportion of physicians with an open claim in any year [24].

Injuries of the type and severity that lead to malpractice claims are sufficiently uncommon in clinical practice that they require a large database for any attempt at systematic study. Malpractice risk is often shared among the involved specialists. Even if specific claims do not reflect cases of directly shared liability, they present opportunities for orthopaedic surgeons to learn from anesthesia-related injuries to their patients in the perioperative period with a goal of developing strategies for their prevention. There is a small body of literature examining orthopaedic surgery malpractice claims directly for potential insights into patient safety [26]. The indirect approach of examining nonspine orthopaedic malpractice claims through the anesthesia malpractice lens adopted here can supplement the existing literature and is more likely to capture claims that arise in part from problems of coordination of care and communication between anesthesia and surgical teams. The specific claims and injuries explored in depth through the questions in this study were chosen based on their impact, potential preventability, and their significance to both anesthesia and orthopaedic teams.

This study specifically addresses the differences in patient and procedure characteristics between claims associated with orthopaedic surgery and claims associated with other procedures as well as differences in events leading to claims, patient injuries, and physician liability. We used the Anesthesia Closed Claims Project database to address the following questions: (1) How do nonspine orthopaedic anesthetic malpractice claims differ from other anesthesia claims with regard to patient and case characteristics, common events and injuries, and liability profile? (2) What are the characteristics of patients who had neuraxial hematomas after spinal and epidural anesthesia for orthopaedic procedures? (3) What are the characteristics of patients who had orthopaedic anesthesia malpractice claims for central ischemic neurologic injury occurring during shoulder surgery in the beach chair position? (4) 
What are the characteristics of patients who had malpractice claims for respiratory depression and respiratory arrests in the postoperative period?

\section{Patients and Methods}

The Anesthesia Closed Claims Project database is a retrospective structured collection of closed anesthesia malpractice claims described in detail elsewhere [5] and briefly summarized here. After institutional review board approval, anesthesiologist-reviewers traveled to participating professional liability companies across the United States and abstracted data from closed anesthesia malpractice claims onto detailed data collection instruments utilizing medical records, depositions, expert reviews, and other confidential data in the claim files. Data collected by these reviewers at all participating companies were aggregated into a national database, which was the source of data for this study. Data collection has been ongoing since 1986. The malpractice insurance companies insured over one-third of practicing anesthesiologists in the United States, in mostly private but including some academic practices, and a wide variety of practice settings including hospitals, surgery centers, and offices. The claims include inpatients and outpatients, relatively healthy to severely ill, simple to complex procedures, from urban and rural areas. Claims for damage to teeth or dentures are not included. Information was collected from medical records, expert witness reports, consultant evaluations, claims manager summaries, and legal summaries.

The Anesthesia Closed Claims Project database consists of 10,546 claims for events that occurred in 1970 to 2013. For purposes of this analysis, claims were included if the event occurred in the year 2000 or later (to exclude claims that might not represent current practice) and the claim was classified as either surgical or related to postoperative pain management $(\mathrm{n}=2067)$. Claims for obstetric anesthesia $(\mathrm{n}=263)$, chronic pain management $(\mathrm{n}=534)$, and critical care or resuscitation $(\mathrm{n}=56)$ were not included (Fig. 1).

Claims related to nonspine orthopaedic surgery $(\mathrm{n}=$ 475 ) included all claims in which the care provided was for upper and lower extremities (including the hip). All other surgical or postoperative claims, including spine surgery, were included in the nonorthopaedic anesthesia claim group $(\mathrm{n}=1592)$.

This is a retrospective analysis of secondary data and, consequently, no experiment, treatment, or specific surgery was used.

Data collected included patient demographics, details regarding anesthesia care, type of surgery, patient outcomes, and legal outcomes. While gathering data from insurance company files, the on-site reviewer evaluated the standard of care, patient's outcome and severity of injury, and the cause of injury (that is, damaging event) and also summarized the claim in a brief narrative, including the sequence of events and causes of injury.

Damaging events were classified into six groups: respiratory events (such as difficult intubation, aspiration, or inadequate oxygenation/ventilation), cardiovascular events (for example, embolic events or massive hemorrhage), regional block events (such as high blocks/total spinals or epidural hematoma formation), events specifically related to surgical care or the patient's presenting health condition, wrong side/location/patient/procedure events, and other damaging events (for example, equipment problems, medication events, positioning, patient fell or was dropped, or failure to diagnose). American Society of Anesthesiologists (ASA) physical status is a classification system used to identify the presenting health status of a patient before making a decision about anesthesia or surgical care to be provided. Generally healthy patients were classified as $1-2$; patients with more substantial comorbidities representing increased anesthesia risk were classified as ASA 3-5. Trauma was defined as a patient presenting to the emergency department or operating room for initial management of blunt trauma, penetrating trauma, burns, drowning, inhalation injuries, or environmental injuries.

The severity of injury score used the National Association of Insurance Commissioners' 10-point scale, which ranges from 0 (no apparent injury) to 9 (death) [38]. This scale was collapsed into three clinically relevant categories for this analysis based on the scale definitions of temporary versus permanent and disabling versus nondisabling: death (score $=9$ ); permanent disabling injuries (score $=6-8$ ); and temporary and permanent minor nondisabling injuries (score $=0-5$ ). Respiratory depression was defined using criteria described in detail elsewhere [25].

Appropriateness of anesthesia care was assessed at the time of file review by the on-site reviewer as appropriate (based on reasonable or prudent practice at the time of the event), substandard, or impossible to judge. The reliability of these evaluations has been evaluated in a separate study using independent review of identical claims by multiple reviewers and the resulting kappa value (0.48) met acceptable criteria (moderate agreement beyond chance) [34]. The contribution of anesthesia and surgery to the patient's injury was judged by the on-site reviewer as no contribution or some contribution. The Anesthesia Closed Claims Project Investigator Committee reviewed the claims, and any disagreements in assessments were resolved by Committee members. Anesthesia payments were based on payments made by the anesthesiologists and/or the anesthesiologist's corporation. Payments made to the plaintiff were extracted from the database and 
Fig. 1 Flow diagram showing types of claims meeting inclusion criteria and those not included, leading to the final study sample.

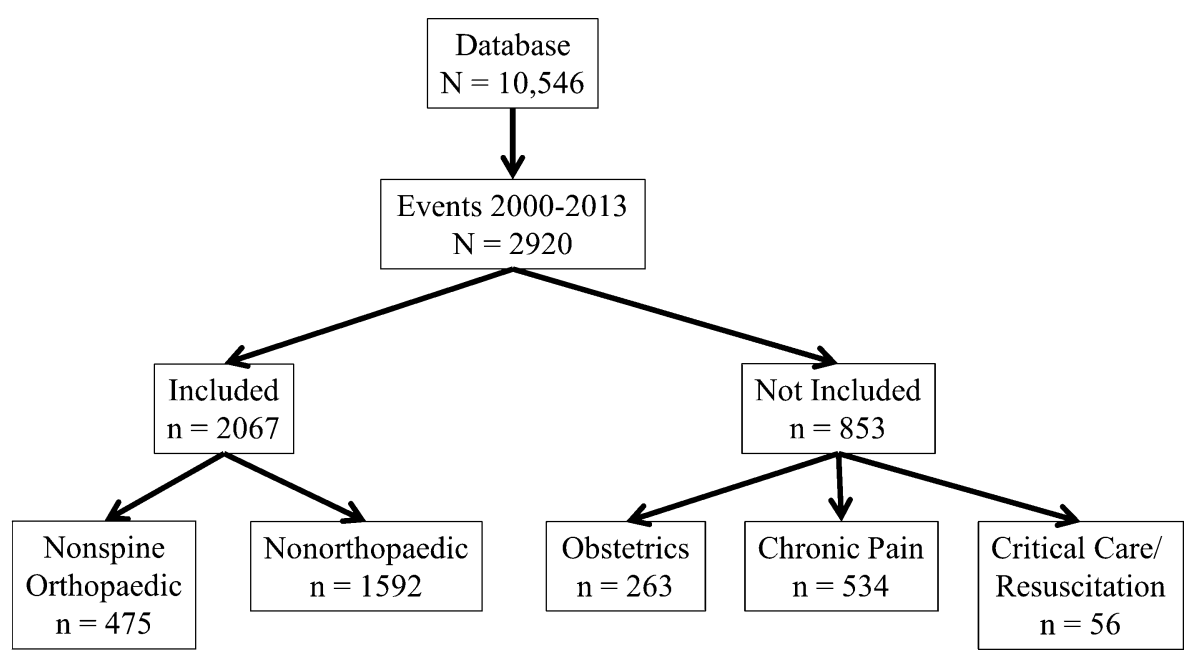

adjusted to US 2015 dollar amounts with the Consumer Price Index [2].

\section{Statistical Analysis}

All missing data were excluded from the analysis on an item-by-item basis. Missing data are indicated on each table by specifying the denominator for each item. Demographics and legal outcomes of claims related to nonspine orthopaedic surgery were compared with claims related to other procedures (including spine cases) using Fisher's exact test, Pearson chi-square, t-test for equality of means, or Mann-Whitney $U$ test with $p<0.05$ as the criterion for statistical significance and two-tailed tests. Median and interquartile range were reported for payments because payments were not normally distributed. Claims with no payment were excluded from calculation of median and interquartile range. No a priori power calculation was conducted; the analyses were based on the available data. All statistical analysis used SPSS 19 for Windows (IBM Corporation, Armonk, NY, USA).

Claims for nonspine orthopaedic procedures consisted of 195 shoulder to hand procedures, 72 hip procedures, and $208 \mathrm{leg}$ to foot procedures. The most common upper extremity procedures were rotator cuff repairs $(n=63)$, other arthroscopic shoulder procedures $(n=55)$, and fracture repairs $(n=23)$. The most common hip procedures were THAs and revisions $(n=49)$ and fracture repairs $(n=$ 19). TKAs and revisions $(n=73)$, arthroscopic knee procedures $(n=50)$, and lower extremity fracture repairs $(n=$ 31) were the most common lower extremity procedures.

Ten orthopaedic patients in the database had claims for epidural hematomas that did not appear to be the result of direct spinal cord trauma during block placement. There were nine orthopaedic patients who experienced central neurologic injury in the setting of shoulder surgery in the beach chair position. For case characteristics in orthopaedic anesthesia malpractice claims for respiratory depression and respiratory arrests in the postoperative period, claims resulting from respiratory depression that occurred while the patient was under the immediate care of an anesthesia provider intraoperatively or on initial arrival to the postanesthesia care unit (PACU) were excluded; 23 patients were identified.

\section{Results}

Nonspine Orthopaedic Anesthetic Malpractice Claims versus Other Anesthesia Claims: Patient and Case Characteristics

Patients undergoing nonspine orthopaedic procedures in anesthesia claims $(n=475)$ were more likely to be generally healthy (ASA physical status 1-2, orthopaedic: 227 [61\%], other: 689 [44\%], odds ratio [OR] 1.99 [1.61-2.46]; $\mathrm{p}<0.001$ ), trauma status (orthopaedic: 69 [15\%], other: 33 [2\%], OR 8.02 [5.22-12.31]; p $<0.001)$, outpatient (orthopaedic: 216 [47\%], other: 427 [27\%], OR 2.36 [1.902.92], $\mathrm{p}<0.001$ ), and less likely emergency (orthopaedic: 32 [7\%], other: 216 [14\%], OR 0.45 [0.31-0.67]; p < 0.001 ) and pediatric (orthopaedic: 10 [2\%], other: 83 [5\%], OR 0.39 [0.20-0.76], $\mathrm{p}=0.002$; Table 1) compared with patients with anesthesia malpractice claims in other procedures $(\mathrm{n}=1592)$. Regional anesthesia was more commonly used in nonspine orthopaedic claims than in anesthesia malpractice claims for other procedures (orthopaedic: 218 [46\%], other: 136 [9\%], OR 9.05 [7.04-11.64]; $\mathrm{p}<0.001$ ). With regard to damaging events, orthopaedic anesthesia claims were more likely related to regional blocks as well as to wrong site surgery (regional block, 
Table 1. Patient and case characteristics for nonspine orthopaedic versus other anesthesia claims*

\begin{tabular}{|c|c|c|c|c|}
\hline Patient and case characteristics & $\begin{array}{l}\text { Orthopaedic anesthesia claims } \\
(\mathrm{n}=475) \\
\text { Number }(\%)\end{array}$ & $\begin{array}{l}\text { Other claims } \\
(\mathrm{n}=1592) \\
\text { Number }(\%)\end{array}$ & Odds ratio $(95 \% \mathrm{CI})$ & $\mathrm{p}$ value \\
\hline \multicolumn{5}{|l|}{ Patient characteristics } \\
\hline Males $(n=2065)$ & $243(51)$ & $758(48)$ & $1.15(0.94-1.41)$ & 0.100 \\
\hline Obese $(n=1560)$ & $161(46)$ & $560(46)$ & $1.00(0.79-1.27)$ & 0.516 \\
\hline ASA physical status $1-2(\mathrm{n}=2019)$ & $277(61)$ & $689(44)$ & $1.99(1.61-2.46)$ & $<0.001$ \\
\hline Emergency status $(n=2045)$ & $32(7)$ & $216(14)$ & $0.45(0.31-0.67)$ & $<0.001$ \\
\hline Trauma patient $(\mathrm{n}=2045)$ & $69(15)$ & $33(2)$ & $8.02(5.22-12.31)$ & $<0.001$ \\
\hline Outpatient $(\mathrm{n}=2023)$ & $216(47)$ & $427(27)$ & $2.36(1.90-2.92)$ & $<0.001$ \\
\hline Patient age $<17$ years & $10(2)$ & $83(5)$ & $0.39(0.20-0.76)$ & 0.002 \\
\hline Age (years), mean $\pm \mathrm{SD}(\mathrm{n}=2046)$ & $53 \pm 16$ & $50 \pm 19$ & $1.01(1.00-1.02)$ & 0.001 \\
\hline Category of care involved in claim & & & & $<0.001$ \\
\hline Postoperative pain management ${ }^{\dagger}$ & $119(25)$ & $117(7)$ & $4.21(3.18-5.58)$ & \\
\hline Primary anesthetic provided $(n=2062)$ & & & & $<0.001$ \\
\hline General anesthesia & $243(51)$ & 1207 (76) & $0.33(0.27-0.41)$ & \\
\hline Regional anesthesia with or without GA & $218(46)$ & $136(9)$ & $9.05(7.04-11.64)$ & \\
\hline Other anesthesia ${ }^{*}$ & $14(3)$ & $244(15)$ & $0.17(0.10-0.29)$ & \\
\hline
\end{tabular}

*All claim events occurred in the year 2000 or later; $\mathrm{N}=2067$ unless noted otherwise; claims with missing data excluded; $\mathrm{p}$ values by Fisher's exact test and chi-square for proportions and t-test (age); ${ }^{\dagger}$ postoperative pain management compared with surgical claims; ${ }^{\star}$ other anesthesia included 237 claims for monitored anesthesia care and 21 claims in which no anesthesia was provided; CI = confidence interval; ASA = American society of Anesthesiologists; GA = general anesthesia.

orthopaedic: 125 [26\%], other: 87 [6\%], OR 6.18 [4.598.32]; wrong site, orthopaedic: 31 [7\%], other: 11 [1\%], OR 10.04 [5.00-20.12]; $\mathrm{p}<0.001)$ and less likely related to respiratory events (orthopaedic: 94 [20\%], other: 401 [26\%], OR 0.73 [0.57-0.94], p < 0.001; Table 2). With regard to mortality and morbidity, orthopaedic claims were less likely related to death and more likely related to minor injury (death, orthopaedic: 112 [24\%], other: 555 [35\%], OR 0.58 [0.46-0.73]; minor injury, orthopaedic: 247 [52\%], other: 626 [39\%], OR 1.67 [1.36-2.05], p < 0.001; Table 2). Finally, for liability characteristics, orthopaedic anesthesia claims had lower odds of the surgeon contributing to the patient's injury (orthopaedic: 86 [45\%], other: 418 [58\%], OR 0.61 [0.44-0.83], p=0.001) and less likely that anesthesia payment was made (orthopaedic: 211 [44\%], other: 845 [53\%], OR 0.71 [0.57-0.87], $\mathrm{p}=0.001$ ).

\section{Neuraxial Hematomas After Neuraxial Anesthesia}

In nine of the 10 claims for hematoma after neuraxial anesthesia, there were delays significantly greater than 8 hours from the earliest documentation of the presenting symptoms and surgical decompression while in the tenth claim, there was insufficient detail to determine the time between presentation and decompression (Table 3 ). The mean age of the patients in these claims was 78 years with a range of 58-97 years. Eight of the claims were associated with epidural anesthesia and two with spinal anesthesia (Table 3). One of the hematomas related to spinal anesthesia occurred when the anesthesia provider was unaware that the patient had received enoxaparin because of charting problems. The other occurred after a spinal anesthetic was chosen for a patient with borderline platelet number $\left(90,00010^{3} / \mu \mathrm{L}\right)$ and recent use of acetylsalicylic acid. Nine of the patients were receiving at least one anticoagulant medication and four were taking combinations of anticoagulants. There were five claims in this review in which a neuraxial hematoma occurred where the American Society of Regional Anesthesia (ASRA) guidelines were not followed (Table 3). In the claims where the ASRA guidelines were not followed, there appeared to have been problems in communication between the anesthesia team or individual managing the epidural and the team or individual managing the anticoagulant regimen, particularly with regard to the timing of epidural catheter removal. The presenting symptoms in this series of 10 epidural hematomas included atypically severe back pain and lower extremity weakness greater than should have been expected with the local anesthetic concentration in the epidural infusion. The hematomas resulted in permanent paraplegic deficits in all of these claims and the severity of injury was reflected in the payments for damages. There were two claims in which no payment was made by the 
Table 2. Damaging events, outcomes, and liability for nonspine orthopaedic versus other anesthesia claims*

\begin{tabular}{|c|c|c|c|c|}
\hline Factors & $\begin{array}{l}\text { Orthopaedic anesthesia claims } \\
(\mathrm{n}=475) \\
\text { Number }(\%)\end{array}$ & $\begin{array}{l}\text { Other claims } \\
(\mathrm{n}=1592) \\
\text { Number }(\%)\end{array}$ & Odds ratio $(95 \% \mathrm{CI})$ & $\mathrm{p}$ value \\
\hline Damaging events $(n=2035)$ & & & & $<0.001$ \\
\hline Respiratory events & $94(20)$ & $401(26)$ & $0.73(0.57-0.94)$ & \\
\hline Cardiovascular events & $67(14)$ & $240(15)$ & $0.90(0.67-1.21)$ & \\
\hline Regional block events & $125(26)$ & $87(6)$ & $6.18(4.59-8.32)$ & \\
\hline Surgical events/patient condition & $52(11)$ & $194(12)$ & $0.87(0.63-1.20)$ & \\
\hline Wrong side/location/patient/procedure & $31(7)$ & $11(1)$ & $10.04(5.00-20.12)$ & \\
\hline Other damaging events & $106(22)$ & $627(40)$ & $0.43(0.34-0.54)$ & \\
\hline \multicolumn{5}{|l|}{ Patient outcomes } \\
\hline Death (9) & $112(24)$ & $555(35)$ & $0.58(0.46-0.73)$ & $<0.001$ \\
\hline Any permanent severe injury (6-8) & $116(24)$ & $411(26)$ & $0.93(0.73-1.18)$ & \\
\hline Only temporary or minor injury $(0-5)$ & $247(52)$ & $626(39)$ & $1.67(1.36-2.05)$ & \\
\hline Severe brain damage $(6-8)$ & $56(12)$ & $177(11)$ & $1.07(0.78-1.47)$ & 0.369 \\
\hline Any nerve injury (1-8) & $125(26)$ & $230(14)$ & $2.12(1.66-2.71)$ & $<0.001$ \\
\hline Severe permanent nerve injury (6-8) & $47(10)$ & $110(7)$ & $1.48(1.03-2.12)$ & 0.022 \\
\hline \multicolumn{5}{|l|}{ Liability characteristics } \\
\hline Substandard care $(\mathrm{n}=1850)$ & $175(41)$ & $640(45)$ & $0.83(0.67-1.04)$ & 0.055 \\
\hline Anesthesiologist contributed to patient's injury $(\mathrm{n}=1797)$ & $333(81)$ & $1109(80)$ & $1.07(0.81-1.41)$ & 0.354 \\
\hline Surgeon contributed to patient's injury $(\mathrm{n}=914)$ & $86(45)$ & $418(58)$ & $0.61(0.44-0.83)$ & 0.001 \\
\hline Anesthesia payment was made ${ }^{\dagger}$ & $211(44)$ & $845(53)$ & $0.71(0.57-0.87)$ & 0.001 \\
\hline Median payment (2015 USD) $)^{\dagger}$ & USD 272,500 & USD 261,360 & NA & 0.523 \\
\hline $25 \%$ quartile & USD 50,250 & USD 75,200 & & \\
\hline $75 \%$ quartile & USD 670,000 & USD 685,000 & & \\
\hline
\end{tabular}

*All claim events occurred in the year 2000 or later; $N=2067$ unless noted otherwise; claims with missing data excluded; $p$ values by chi square, Fisher's exact test, and Mann-Whitney U-test (payment amount); ${ }^{\dagger}$ claims paid and median payments include payments by anesthesiologist and anesthesiologist's corporation; $\mathrm{CI}=$ confidence interval; $\mathrm{NA}=$ not applicable.

anesthesiologist/corporation and the range for the payments was USD 101,562 to USD $1,370,000$ with a median payment of USD 351,000 .

Central Ischemic Neurologic Injury During Shoulder Surgery in the Beach Chair Position

There is no single patient characteristic or intraoperative factor identifiable in all claims with central ischemic neurologic injury in the beach chair position (Table 4). The apparent failure of the providers to consider the difference in blood pressure at the arm or the even larger difference between the blood pressure as measured in the leg and the actual cerebral perfusion pressure in the upright position was felt to be an important factor by many of the expert reviewers of these claims. Perhaps the most that could be expected from a series such as this is the identification of a strong qualitative association with a specific patient comorbidity, anesthetic, or monitoring technique. For example, if all the patients in the series were of advanced age or had a history of chronic hypertension, coronary artery disease, peripheral vascular disease, or intraoperative use of high doses of antihypertensive medications, one or more of these factors could possibly serve as warning flags for prevention of these catastrophic complications. The claims encompassed anesthetics in which intraoperative hypotension appeared to be an intentional goal in an effort to improve operating conditions, whereas in other claims, the anesthesia provider appeared to have difficulty in overcoming severe hypotension that was an undesired side effect of the anesthetic and patient position rather than the consequence of a deliberate anesthetic technique. Four of the patients in our series had documented anomalies in cerebral circulation, two with incomplete formation of the circle of Willis, one with a hypoplastic vertebral artery, and one with $60 \%-79 \%$ stenosis of a carotid artery. 
Table 3. Characteristics of claims for neuraxial hematomas after spinal and epidural anesthesia for nonspine orthopaedic procedures*

\begin{tabular}{|c|c|}
\hline Factor & Number $(\%)$ \\
\hline Age (years), mean $\pm \mathrm{SD}$ & $78 \pm 12$ \\
\hline Male & $5(50)$ \\
\hline \multicolumn{2}{|l|}{ Preoperative conditions } \\
\hline ASA physical status $1-2$ (generally healthy) & $3(30)$ \\
\hline Obesity $(\mathrm{n}=8)$ & $2(25)$ \\
\hline \multicolumn{2}{|l|}{ Procedure } \\
\hline TKA & $6(60)$ \\
\hline Fracture repair & $3(30)$ \\
\hline THA/revision & $1(10)$ \\
\hline \multicolumn{2}{|l|}{ Type of block } \\
\hline Epidural & $8(80)$ \\
\hline Spinal & $2(20)$ \\
\hline Patient was receiving anticoagulants & $9(90)$ \\
\hline \multicolumn{2}{|l|}{ Timing of recognition of hematoma } \\
\hline Day of surgery & $1(10)$ \\
\hline Postoperative day 1 & $1(10)$ \\
\hline Postoperative day 2 & $3(30)$ \\
\hline Postoperative day 3 & $2(20)$ \\
\hline Postoperative day 4 & $2(20)$ \\
\hline Postoperative day 5 & $1(10)$ \\
\hline $\begin{array}{l}>8 \text { hours between symptoms and surgical } \\
\text { decompression }(n=9)\end{array}$ & $9(100)$ \\
\hline $\begin{array}{l}\text { Injury resulted in permanent and severe } \\
\text { paraplegia }\end{array}$ & $10(100)$ \\
\hline \multicolumn{2}{|c|}{$\begin{array}{l}\text { American Society of Regional Anesthesiologists guidelines were } \\
\text { followed }(\mathrm{n}=8)\end{array}$} \\
\hline No & $5(63)$ \\
\hline \multicolumn{2}{|l|}{ Liability } \\
\hline Anesthesia payment was made ${ }^{\dagger}$ & $8(80)$ \\
\hline Median payment $\left(2015\right.$ USD) ${ }^{\dagger}$ & USD 351,000 \\
\hline Payment range & $\begin{array}{l}\text { USD } 101,562-U S D \\
\quad 1,370,000\end{array}$ \\
\hline
\end{tabular}

$* \mathrm{~N}=10$ unless stated otherwise; missing data excluded; ${ }^{\dagger}$ claims paid and median payments include payments by anesthesiologist and anesthesiologist's corporation; claims included no information on payments by surgeons; ASA $=$ American Society of Anesthesiologists.

\section{Respiratory Depression and Respiratory Arrests After Surgery}

There were 14 deaths in 23 orthopaedic claims associated with postoperative respiratory depression and of those 23 patients, eight of $23(35 \%)$ were morbidly obese (body mass index $>40 \mathrm{~kg} / \mathrm{m}^{2}$ ) and eight of $23(35 \%)$ had a diagnosis of obstructive sleep apnea (OSA). TKA was the most common procedure in this group of claims (11 of 23; Table 5). Among the patients with OSA, there were no claims describing the diligent application and use of
Table 4. Characteristics of claims for central ischemic neurologic injury during shoulder surgery in the beach chair position*

\begin{tabular}{ll}
\hline Factor & Number (\%) \\
\hline Age (years), mean \pm SD & $52 \pm 6.5$ \\
Male & $4(44)$ \\
ASA physical status 1-2 (generally & $6(67)$ \\
$\quad$ healthy) & \\
Preoperative conditions & $3(33)$ \\
Chronic hypertension & $2(22)$ \\
Elevated preoperative blood pressure & $6(67)$ \\
Obesity & $4(44)$ \\
Vascular abnormality & \\
Anesthetic/surgical management & $2(22)$ \\
Lower extremity blood pressure cuff & $5(56)$ \\
Intraoperative hypotension (intentional \\
or not)
\end{tabular}

*N $=9$ unless stated otherwise; missing data excluded; ${ }^{\dagger}$ claims paid and median payments include payments by anesthesiologist and anesthesiologist's corporation; claims included no information on payments by surgeons; ASA $=$ American Society of Anesthesiologists.

continuous positive airway pressure in the postoperative period. All of these claims involved opioid administration for postoperative pain relief. Patient-controlled analgesia (PCA) with intravenous opioid dosing was used in 17 of these 23 claims (74\%), including five in which a continuous basal infusion was ordered with the PCA. One of the recurring narratives in the claims was difficulty in establishing pain control and/or controlling nausea or itching leading to a change in opioid orders and then at times the coadministration of other potentially sedating adjunct medications. These order changes usually included dose escalation with no change in the intensity or frequency of respiratory monitoring. There were also instances of the use of continuous infusions of opioids in opioid-naïve patients. If oxygen saturation monitoring was used, it was usually intermittent in its application and even in the claims in which continuous monitoring appears to have been used, its value was questionable because low-saturation event alarms appeared to be limited to the patient's room with no remote telemetric monitoring. The highest risk time period for the occurrence of the events appeared to be postoperative day 1 , particularly in the early morning. There were, however, two events that occurred at least 24 hours postsurgery. There was one ambulatory procedure postdischarge death, which occurred in a setting of an unusually brief monitoring period in the PACU and 
Table 5. Case characteristics in nonspine orthopaedic anesthesia malpractice claims for respiratory depression and respiratory arrests in the postoperative period*

\begin{tabular}{ll}
\hline Factor & Number $(\%)$ \\
\hline Age (years), mean \pm SD & $56 \pm 14$ \\
Male & $12(52)$ \\
ASA physical status $1-2$ (generally healthy) & $11(50)$ \\
$\quad$ n = 22) & \\
Preoperative conditions & $10(63)$ \\
Sleep apnea (n $=16)$ & $13(68)$ \\
Obesity (n = 19) & \\
Procedure & $11(48)$ \\
TKA & $4(17)$ \\
THA/revision & $5(22)$ \\
Other lower extremity procedures & \\
Upper extremity surgery & \\
Timing of respiratory event & $3(13)$ \\
Day of surgery & \\
Postoperative day 1 & $8(35)$ \\
Postoperative day 2 & $14(61)$ \\
Postoperative opioids given & \\
Morphine & $1(4)$ \\
Hydromorphone &
\end{tabular}

$* \mathrm{~N}=23$ unless stated otherwise; missing data excluded; ${ }^{\dagger}$ other lower extremity procedures included: two knee arthroscopic procedures and three fracture repairs; ${ }^{*}$ upper extremity procedures included: one rotator cuff repair, one biceps tendon repair, and one fracture repair; ${ }^{\S}$ opioids sum to greater than $100 \%$ because 15 patients received more than one opioid; other opioids consisted of fentanyl, hydrocodone, oxycodone, acetaminophen/oxycodone, and other unspecified opioids; "claims paid and median payments include payments by anesthesiologist and anesthesiologist's corporation; claims included no information on payments by surgeons; ASA = American Society of Anesthesiologists. administration of a high dose of intravenous hydromorphone in the PACU to a patient with OSA.

\section{Discussion}

Anesthesiologists have utilized analysis of malpractice claims to identify anesthesia-related patient safety issues and improve practice [3]. Analysis of malpractice claim data can be used to investigate patient safety events arising during the care of orthopaedic patients and can provide insight into the medicolegal liability shared by the two specialties. Nonspine orthopaedic anesthesia malpractice claims were more frequently associated with nerve injuries and events arising from the use of regional anesthesia than in malpractice claims in other areas of anesthesia malpractice.

This study has a number of limitations. First, closed claims data do not provide denominator data, making estimates of risk impossible to determine. Malpractice claims are more likely to be filed when the injury the patient experienced is severe and permanent resulting in a higher proportion of severe permanent injuries in our database than actually occurs in clinical practice. The reviewer evaluation of the quality of anesthesia care has been demonstrated to be acceptable (kappa $=0.48$ ) but not excellent [34]. Analysis of closed claims is by necessity retrospective. The sample is large yet represents an opportunity sample, because not all companies consent to participation; we do not know if the geographic distribution of claims and characteristics of the insureds (private versus academic, urban versus rural, etc) are representative of anesthesiologists in the United States. Information gathered by the malpractice insurance companies was for the purpose of resolving claims, not for patient safety research. Data are sometimes missing from the files; files with insufficient information to reconstruct the nature of the complaint, often closed for inactivity, are not included in the database. Because this analysis was drawn from claims filed against anesthesiologists, the information on the orthopaedic surgeons' contribution to the patients' injury and liability is underestimated. Information on the surgeon's liability is most often available only in those claims in which both the surgeon and anesthesiologist were insured by the same malpractice company. Despite these limitations, analysis of a large national closed claims database provides an opportunity to reveal important factors contributing to liability and patient safety that are otherwise difficult to study by other methods $[3,5]$.

Liability arising from regional block-related events represented $26 \%$ of all nonspine orthopaedic anesthesia claims in this series. Regional anesthesia has been recognized as providing many potential advantages relative to 
general anesthesia for orthopedic surgery [28]. This association between the use of regional anesthesia and orthopaedic surgery is reflected in the liability claim data in this review because $26 \%$ of the claims were for blockrelated damaging events. There is evidence that this association may simply reflect the relative frequency of the use of blocks in orthopaedic surgeries because retrospective reviews suggested that there was at least no increase in the frequency of nerve injury when regional anesthesia was used for THA, TKA, and total shoulder arthroplasty [22, 23, 41]. Matsen et al. [26] used the closed claims data from a single large malpractice insurer to examine the injuries associated with orthopaedic surgeons' malpractice claims and found that block-related events represented $<$ $1 \%$ of the claims. The difference between the liability for block-related events for anesthesiologists and orthopaedic surgeons $(26 \%$ versus $<1 \%)$ in these series would suggest that the liability process does not hold the orthopaedic surgeon vicariously liable for the frequently shared decision to use a regional anesthetic.

The risks of regional anesthesia and anticoagulation with orthopaedic surgery were evident in this malpractice claim review and highlight important clinical issues. The potential benefits of primary regional anesthesia for major orthopaedic procedures continue to be acknowledged; however, the role of epidural infusion analgesia in the postoperative period has been questioned as peripheral nerve block and surgical techniques have improved and concerns have been raised about mixing epidurals and deep vein thrombosis prophylaxis $[6,8,13]$. Perioperative anticoagulant use for orthopaedic procedures is ubiquitous and this is reflected in the fact that all but one of the hematomas occurred in conjunction with the use of one or more anticoagulants. The ASRA has published guidelines for the management of thromboembolic prophylaxis regimens and concomitant use of neuraxial anesthesia [20, 21]. The claims in this review occurred in the year 2000 or later, after the initial guidelines were published. The five claims for neuraxial hematoma that did not adhere to the guidelines violated recommendations in the 1998 guidelines, which have not changed substantially in the intervening years. Although hematomas have occurred in patients with no recognized pharmacologically induced or medical coagulopathy, there are indications that the risk of hematoma is increased in patients with altered coagulation. Gulur et al. [18] estimated the incidence of hematoma for patients with abnormal coagulation factors to be one in 315 patients (95\% confidence interval, 87-2597), whereas Ehrenfeld et al. [11] reported an incidence of one in 7143 in their series when their calculations included patients with abnormal coagulation profiles and one in 10,800 when only patients with normal coagulation parameters were included. Consensus opinion and data from these two studies would suggest that some if not all of the complications may have been prevented had the ASRA guidelines been followed. However, adherence to widely recognized anticoagulant/neuraxial anesthesia guidelines is not sufficient to eliminate problems, because neuraxial hematomas occurred during care where guidelines were followed and in instances where no anticoagulants were used. This mirrors the experience reported by Pitkanen et al. [32] whose claims review in Finland included 13 neuraxial hematoma claims. In seven of these claims, hematomas occurred when no anticoagulants were used or in instances where present anticoagulant guidelines were followed. There were no claims associated with good outcomes in this series so analysis of these claims cannot shed any direct light on the possible effectiveness of close monitoring, early diagnosis, and intervention for hematoma decompression in the prevention of injuries.

The catastrophic nature of central nervous system ischemic injuries keeps them at the forefront of consciousness of anesthesiologists caring for patients in the beach chair position, but their occurrence appears to be rare and appears to evade prediction. Through medicolegal review of malpractice claims, Pohl and Cullen [33] identified a series of four patients who experienced cerebral or spinal cord ischemia after shoulder surgery in the sitting position. The authors noted that none of these patients had major risk factors for stroke aside from male gender (two patients) and hyperlipidemia (one patient) and they expressed the opinion that reduced cerebral perfusion in the sitting position was causally related to these injuries. A survey of 93 shoulder and elbow surgeons by Friedman et al. [14] captured eight surgeon-reported events of intraoperative central ischemic neurologic injury in the beach chair position. These authors used estimates to create a denominator and incidence for this type of injury during shoulder surgery of eight of 274,225 (0.00291\%). Interestingly, even in the absence of any report in their survey of an ischemic injury during shoulder surgery in the lateral position, the authors indicated that their statistical modeling did not indicate that the sitting position represented a greater risk than the lateral position for ischemic neurologic injury. This opinion is in direct opposition to that of Pohl and Cullen and that of many of the experts who reviewed the closed claims in our series. Incomplete circle of Willis has been cited as a risk factor for stroke; it is, however, not an identifiable condition in routine preoperative testing for shoulder surgery [19, 42].

Our review of postoperative respiratory depression and respiratory arrests found that these types of events resulted in death or severe brain damage, occurred within the first 24 hours of surgery, and were preventable. These findings were similar to those of Lee at al. [25] in their comprehensive review of opioid-induced postoperative respiratory 
depression claims that was not limited to orthopedic claims. A review of a number of studies on the prevalence of OSA and morbid obesity in orthopaedic patients, including three studies using data from the Nationwide Inpatient Sample, would suggest that morbid obesity and OSA appeared to be overrepresented among patients in this series of malpractice claims for injuries resulting from postoperative respiratory depression events $[1,9,12,27,29]$. OSA was found in $5.6 \%$ of undifferentiated orthopaedic surgery patients [29] and $6.4 \%$ of patients who underwent revision joint arthroplasty [9]. Obesity, not further defined, was reported in $13 \%$ of the over 3 million patients in a study examining outcomes after TKA between 1998 and 2006 [27]. Opperer et al. [31] published a systematic review of the effect of OSA on perioperative outcomes, which included studies of orthopaedic procedures. An association was found between OSA and postoperative respiratory complications, including hypoxic episodes after TKA and THA. These events are, of course, associated with opioid-based postoperative analgesic regimens, particularly intravenous PCA, but the significant features appear to be the specific PCA settings and concomitant use of sedating adjuncts. The use of a continuous basal rate on an intravenous PCA can compromise the safety of a patient-controlled technique, because excessive sedation should limit self-administered boluses, which will result in opioid dose reduction, but with a continuous basal rate, the opioid will still accumulate while the patient becomes increasingly sedated. There appeared to have been failures to recognize the risk for severe respiratory depression and failure to implement closer respiratory monitoring triggered by risk factors or by the occurrence of premonitory moderate respiratory depression events before the injury that led to the claim.

We found several systematic differences between nonspine orthopaedic anesthesia claims and other anesthesia malpractice claims; specifically, the patients in nonspine orthopaedic malpractice claims were more likely to be presenting for outpatient surgery, trauma, and to receive regional anesthesia. In contrast to the association with regional anesthesia suggested by this series, a separate review of malpractice claims with orthopaedic surgeons as the primary defendants indicated that "block-related events" were a relevant part of the claims $<1 \%$ of the time [26]. We chose to focus much of our review on claims with severe injuries that arise in the context of shared intraoperative and postoperative decision-making and communication between orthopaedic surgeons and anesthesiologists. Epidural hematoma after neuraxial anesthesia presented with atypically severe back pain and unexpected motor block in settings where anticoagulants and blocks were timed and managed both in accordance with existing nationally recognized guidelines and in violation of those guidelines [20]. The claims for postoperative respiratory depression were associated with severe injuries and appeared to be possibly preventable with heightened awareness of risk factors such as OSA and the utilization of closer respiratory monitoring. The review of claims for intraoperative central neurologic ischemic injury in surgeries in the sitting position did not reveal any specific cluster of risk factors for stroke or other preoperatively identifiable patient characteristics that might alert surgeons and anesthesiologists to an enhanced risk of this rare and catastrophic injury. Close attention should be paid to the difference between measured blood pressure and cerebral perfusion pressure for patients in the sitting position when practitioners are either aiming for a specific blood pressure intentionally or attempting to treat hypotension as a side effect of anesthesia [10, 30].

Acknowledgments We acknowledge the closed claims reviewers from the ASA and participation of the following liability insurance companies who have given permission to be acknowledged: Anesthesia Service Medical Group, Inc, San Diego, CA, USA; COPIC Insurance Company, Denver, CO, USA; ISMIE Mutual Insurance Company, Chicago, IL, USA; MAG Mutual Insurance Company, Atlanta, GA, USA; Medical Liability Mutual Insurance Company, New York, NY, USA; Midwest Medical Insurance Company, Minneapolis, MN, USA; NORCAL Mutual Insurance Company, San Francisco, CA, USA; Physicians Insurance A Mutual Company, Seattle, WA, USA; Preferred Physicians Medical Risk Retention Group, Overland Park, KS, USA; Risk Management Foundation, Cambridge, MA, USA; State Volunteer Mutual Insurance Company, Brentwood, TN, USA; The Doctors' Company, Napa, CA, USA; and The University of Texas System, Austin, TX, USA.

\section{References}

1. Böstman OM. Prevalence of obesity among patients admitted for elective orthopaedic surgery. Int J Obes Relat Metab Disord. 1994;18:709-713.

2. Bureau of Labor Statistics, US Department of Labor. Consumer Price Index inflation calculator. Available at: http://www.bls.gov/ data/home.htm. Accessed November 1, 2016.

3. Cheney FW. The American Society of Anesthesiologists Closed Claims Project: what have we learned, how has it affected practice, and how will it affect the future? Anesthesiology. 1999;91:552-556.

4. Cheney FW. The American Society of Anesthesiologists Closed Claims Project: the beginning. Anesthesiology. 2010;113:957960.

5. Cheney FW, Posner K, Caplan RA, Ward RJ. Standard of care and anesthesia liability. JAMA. 1989;261:1599-1603.

6. Choi PT, Bhandari M, Scott J, Douketis J. Epidural analgesia for pain relief following hip or knee replacement. Cochrane Database Syst Rev. 2003;3:CD003071.

7. Cook TM, Bland L, Mihai R, Scott S. Litigation related to anaesthesia: an analysis of claims against the NHS in England 1995-2007. Anaesthesia. 2009;64:706-718.

8. Cook TM, Counsell D, Wildsmith JAW, Royal College of Anaesthetists Third National Audit Project. Major complications of central neuraxial block: report on the Third National Audit Project of the Royal College of Anaesthetists. Br J Anaesth. 2009;102:179-190. 
9. D’Apuzzo MR, Browne JA. Obstructive sleep apnea as a risk factor for postoperative complications after revision joint arthroplasty. J Arthroplasty. 2012;27:95-98.

10. Drummond JC. The lower limit of autoregulation: time to revise our thinking? Anesthesiology. 1997;86:1431-1433.

11. Ehrenfeld JM, Agarwal AK, Henneman JP, Sandberg WS. Estimating the incidence of suspected epidural hematoma and the hidden imaging cost of epidural catheterization: a retrospective review of 43,200 cases. Reg Anesth Pain Med. 2013;38:409-414.

12. Finkel KJ, Searleman AC, Tymkew H, Tanaka CY, Saager L, Safer-Zadeh E, Bottros M, Selvidge JA, Jacobsohn E, Pulley D, Duntley S, Becker C, Avidan MS. Prevalence of undiagnosed obstructive sleep apnea among adult surgical patients in an academic medical center. Sleep Med. 2009;10:753-758.

13. Fowler SJ, Symons J, Sabato S, Myles PS. Epidural analgesia compared with peripheral nerve blockade after major knee surgery: a systematic review and meta-analysis of randomized trials. Br J Anaesth. 2008;100:154-164.

14. Friedman DJ, Parnes NZ, Zimmer Z, Higgins LD, Warner JJ. Prevalence of cerebrovascular events during shoulder surgery and association with patient position. Orthopedics. 2009;32:256-261.

15. Greenberg CC, Regenbogen SE, Studdert DM, Lipsitz SR, Rogers SO, Zinner MJ, Gawande AA. Patterns of communication breakdowns resulting in injury to surgical patients. $J$ Am Coll Surg. 2007;204:533-540.

16. Griffen FD, Stephens LS, Alexander JB, Bailey HR, Maizel SE, Sutton BH, Posner KL. The American College of Surgeons' closed claims study: new insights for improving care. J Am Coll Surg. 2007;204:561-569.

17. Griffen FD, Stephens LS, Alexander JB, Bailey HR, Maizel SE, Sutton BH, Posner KL. Violations of behavioral practices revealed in closed claims reviews. Ann Surg. 2008;248:468-474.

18. Gulur P, Tsui B, Pathak R, Koury KM, Lee H. Retrospective analysis of the incidence of epidural haematoma in patients with epidural catheters and abnormal coagulation parameters. $\mathrm{Br} J$ Anaesth. 2015;114:808-811.

19. Hoksbergen AW, Legemate DA, Csiba L, Csáti G, Síró P, Fülesdi B. Absent collateral function of the circle of Willis as risk factor for ischemic stroke. Cerebrovasc Dis. 2003;16:191-198.

20. Horlocker TT, Wedel DJ. Anticoagulation and neuraxial block: historical perspective, anesthetic implications, and risk management. Reg Anesth Pain Med. 1998;23:129-134.

21. Horlocker TT, Wedel DJ, Rowlingson JC, Enneking FK, Kopp SL, Benzon HT, Brown DL, Heit JA, Mulroy MF, Rosenquist RW, Tryba M, Yuan CS. Regional anesthesia in the patient receiving antithrombotic or thrombolytic therapy: American Society of Regional Anesthesia and Pain Medicine EvidenceBased Guidelines (Third Edition). Reg Anesth Pain Med. 2010;35:64-101.

22. Jacob AK, Mantilla CB, Sviggum HP, Schroeder DR, Pagnano MW, Hebl JR. Perioperative nerve injury after total knee arthroplasty: regional anesthesia risk during a 20-year cohort study. Anesthesiology. 2011;114:311-317.

23. Jacob AK, Mantilla CB, Sviggum HP, Schroeder DR, Pagnano MW, Hebl JR. Perioperative nerve injury after total hip arthroplasty: regional anesthesia risk during a 20-year cohort study. Anesthesiology. 2011;115:1172-1178.

24. Jena AB, Seabury S, Lakdawalla D, Chandra A. Malpractice risk according to physician specialty. N Engl J Med. 2011;365:629636.

25. Lee LA, Caplan RA, Stephens LS, Posner KL, Terman GW, Voepel-Lewis T, Domino KB. Postoperative opioid-induced respiratory depression: a closed claims analysis. Anesthesiology. 2015;122:659-665.

26. Matsen FA 3rd, Stephens L, Jette JL, Warme WJ, Posner KL. Lessons regarding the safety of orthopaedic patient care: an analysis of four hundred and sixty-four closed malpractice claims. J Bone Joint Surg Am. 2013;95:e201-208.

27. Memtsoudis SG, Ma Y, Gonzalez Della Valle A, Mazumdar M, Gaber-Baylis LK, MacKenzie CR, Sculco TP. Perioperative outcomes after unilateral and bilateral total knee arthroplasty. Anesthesiology. 2009;111:1206-1216.

28. Memtsoudis SG, Sun X, Chiu YL, Stundner O, Liu SS, Banerjee $S$, Mazumdar M, Sharrock NE. Perioperative comparative effectiveness of anesthetic technique in orthopedic patients. Anesthesiology. 2013;118:1046-1058.

29. Mokhlesi B, Hovda MD, Vekhter B, Arora VM, Chung F, Meltzer DO. Sleep-disordered breathing and postoperative outcomes after elective surgery: analysis of the Nationwide Inpatient Sample. Chest. 2013;144:903-914.

30. Munis JR. The problems of posture, pressure, and perfusion. Anesthesia Patient Safety Foundation Newsletter. 2008;22:82-83.

31. Opperer M, Cozowicz C, Bugada D, Mokhlesi B, Kaw R, Auckley D, Chung F, Memtsoudis SG. Does obstructive sleep apnea influence perioperative outcome? A qualitative systematic review for the Society of Anesthesia and Sleep Medicine Task Force on Preoperative Preparation of Patients with Sleep-Disordered Breathing. Anesth Analg. 2016;122:1321-1334.

32. Pitkanen MT, Aromaa U, Cozanitis DA, Forster JG. Serious complications associated with spinal and epidural anaesthesia in Finland from 2000 to 2009. Acta Anaesthesiol Scand. 2013;57:553-564.

33. Pohl A, Cullen DJ. Cerebral ischemia during shoulder surgery in the upright position: a case series. J Clin Anesth. 2005;17:463469.

34. Posner KL, Sampson PD, Caplan RA, Ward RJ, Cheney FW. Measuring interrater reliability among multiple raters: an example of methods for nominal data. Stat Med. 1990;9:1103-1115.

35. Pukk-Harenstam K, Ask J, Brommels M, Thor J, Penaloza RV, Gaffney FA. Analysis of 23364 patient-generated, physicianreviewed malpractice claims from a non-tort, blame-free, national patient insurance system: lessons learned from Sweden. Qual Saf Health Care. 2008;17:259-263.

36. Rogers SO Jr, Gawande AA, Kwaan M, Puopolo AL, Yoon C, Brennan TA, Studdert DM. Analysis of surgical errors in closed malpractice claims at 4 liability insurers. Surgery. 2006;140:2533.

37. Seabury SA, Chandra A, Lakdawalla DN, Jena AB. On average, physicians spend nearly 11 percent of their 40-year careers with an open, unresolved malpractice claim. Health Aff (Millwood). 2013;32:111-119.

38. Sowka M, ed. Malpractice Claims: Final Compilation. Brookfield, WI, USA: National Association of Insurance Commissioners; 1980.

39. Studdert DM, Bismark MM, Mello MM, Singh H, Spittal MJ. Prevalence and characteristics of physicians prone to malpractice claims. N Engl J Med. 2016;374:354-362.

40. Studdert DM, Mello MM, Gawande AA, Gandhi TK, Kachalia A, Yoon C, Puopolo AL, Brennan TA. Claims, errors, and compensation payments in medical malpractice litigation. $N$ Engl $J$ Med. 2006;354:2024-2033.

41. Sviggum HP, Jacob AK, Mantilla CB, Schroeder DR, Sperling JW, Hebl JR. Perioperative nerve injury after total shoulder arthroplasty: assessment of risk after regional anesthesia. Reg Anesth Pain Med. 2012;37:490-494.

42. van Seeters T, Hendrikse J, Biessels GJ, Velthuis BK, Mali WP, Kappelle LJ, van der Graaf Y, SMART Study Group. Completeness of the circle of Willis and risk of ischemic stroke in patients without cerebrovascular disease. Neuroradiology. 2015;57:1247-1251. 